\title{
Practical approach to exercise-induced bronchoconstriction in athletes
}

\author{
Les Ansley', Glen Rae'2, *James H Hull ${ }^{1,3}$ \\ ${ }^{1}$ School of Life Sciences, Northumbria University, Newcastle upon Tyne, UK \\ 2 Encompass Healthcare Surgery, The Galleries Health Centre, Washington, Tyne and Wear, UK \\ ${ }^{3}$ Department of Respiratory Medicine, Royal Brompton Hospital, London, UK
}

Originally received 5th May 2012; resubmitted 31st July 2012; revised 7th October 2012; accepted 12th October 2012; online 25th February 2013

\begin{abstract}
Exercise-induced bronchoconstriction (EIB) is highly prevalent in athletes of all abilities and can impact on their health and performance. The majority of athletes with exertional dyspnoea will be initially assessed and managed in primary care. This report provides a practical and pragmatic approach to the assessment and management of a young athlete presenting with suspected ElB in this setting.

(C) 2013 Primary Care Respiratory Society UK. All rights reserved.

L Ansley et al. Prim Care Respir J 2013; 22(1): 122-125

http://dx.doi.org/10.4104/pcrj.2013.00004
\end{abstract}

Keywords exercise-induced bronchoconstriction, exercise-induced asthma, asthma, primary care, bronchoprovocation

\section{Clinical case scenario}

A 24-year-old amateur competitive athlete attends complaining of 'difficulty breathing' when training and competing. She says symptoms start shortly after she begins exercising and reports difficulty 'catching her breath'. She also reports hearing occasional wheeze after an exercise session. She has no other medical history and otherwise feels very well.

\section{Introduction}

Sport-related respiratory symptoms are commonly reported by athletes, and differentiating between what is 'physiologically appropriate' and symptoms arising from underlying cardiorespiratory pathology can be difficult. In this case, a key differential diagnosis is exercise-induced bronchoconstriction (EIB) - a transient airway narrowing that occurs in association with exercise.

The term EIB is often used interchangeably with exercise-induced asthma; however, 'ElB' is favoured, since exercise triggers bronchoconstriction but does not induce the clinical syndrome that defines 'asthma'. Moreover, EIB can be a physiological phenomenon occurring in athletes in the absence of other features of asthma, but in others EIB is a sign of untreated asthma.

The pathophysiology of EIB is complex and incompletely understood; however, it is established that exercise hyperpnoea can precipitate EIB by inducing osmotic changes at the distal airway surface - more specifically, by acting to effectively desiccate the airway surface, driving a local osmotic stimulus that results in cell shrinkage leading to ion flux, release of local mediators, and ultimately airway smooth muscle contraction. ${ }^{1}$

The prevalence of EIB is high in athletes of all abilities ( 20\% in both gym attendees ${ }^{2}$ and summer Olympic athletes $\left.{ }^{3,4}\right)$ and has consequences for both health and exercise performance. ${ }^{5}$ Significantly, the approach to diagnosis and management of EIB in primary care appears to conflict with guideline recommendations. ${ }^{6}$

\section{Approach to clinical assessment}

Clinical assessment should focus on evaluating features supporting a diagnosis of EIB, but with diligent consideration for alternative diagnoses such as cardiac pathology. Important aspects to consider include the fact that:

- Symptoms of EIB include shortness of breath, an increased breathing effort, chest tightness, wheeze and/or cough. Athletes may also report reduced performance or increased fatigue.

- The onset of symptoms in EIB classically occurs following a bout of intense exercise (e.g. fast jogging with heart rate $>85 \%$ predicted maximum) that is sustained for longer than a few minutes (usually 5-10 mins).

- Symptoms more prominent on inspiration may indicate transient upper airway obstruction which is termed exerciseinduced laryngeal obstruction. ${ }^{7}$ The latter can mimic EIB,

\footnotetext{
* Corresponding author: Dr James H Hull, Department of Respiratory Medicine, Royal Brompton Hospital, London SW3 6HP, UK.

Tel: +44 (0)207 3518051 Fax: +44 (0)207 3518937 E-mail: jiminio@doctors.org.uk
} 
although typically symptoms are maximal at peak exercise and regress with exercise cessation. An accurate diagnosis of exercise-induced laryngeal obstruction is dependent on direct visualisation of the upper airway during exercise?

- Symptoms usually remit spontaneously within 30 mins and about $50 \%$ of athletes display a refractory period during which respiratory symptoms do not recur with a repeated exercise challenge. ${ }^{8}$ Symptoms may persist, and it is important to note that some symptoms attributed to EIB (e.g. cough) may actually arise from stimulation of sensory nerves within the airway tree (i.e. distinct from bronchoconstriction). ${ }^{9}$

- A diagnosis of EIB is more likely in those with a history of atopy ${ }^{10}$ and in those taking part in certain sports such as swimming and cold weather sports. The role of environmental conditions and specific exposure triggers remains uncertain. There is evidence that exposure to potentially noxious training environments (e.g. pollutants in an indoor skating arena) is detrimental to lung function, but the role of chlorine exposure in the development of EIB remains to be fully determined. ${ }^{.1}$ Certainly, symptoms in atopic individuals may be potentiated by exercise when exposed to the relevant sensitising aeroallergen.

Clinical examination in the consulting room will often provide little further evidence to secure or refute the diagnosis of EIB because features occur in the setting of exertion. It is important, however, to perform a cardiorespiratory examination to exclude alternative diagnoses (e.g. auscultate for a cardiac murmur).

The differential diagnosis for EIB is broad, although other diagnoses such as cardiac dysfunction or physical deconditioning typically precipitate symptoms that are maximal during exercise and improve with exercise cessation.

\section{Investigation}

EIB may be strongly suspected by an appropriate history. However, exercise-related respiratory symptoms actually have a poor predictive value for the diagnosis of EIB compared with objective testing..$^{12,13}$ Indeed, a study evaluating the relationship between symptoms and field exercise testing revealed that a clinical-based diagnosis is likely to be as accurate as a coin toss. ${ }^{14}$ The reasons for this remain unclear, ${ }^{15}$ although this poor relationship may be explained in part by the accuracy of diagnostic methods, altered perception of symptoms, and genesis of symptoms from airway pathology distinct from EIB. A secure diagnosis therefore depends on confirmatory investigation (Figure 1).

- Peak flow measurements are not an accurate means of evaluating airway physiology in athletes and are therefore not recommended.

- If resting spirometry demonstrates airflow obstruction, a bronchodilator challenge should be performed looking for evidence of reversibility of this obstruction (i.e. $>12 \%$ and $200 \mathrm{ml}$ increase in the forced expiratory volume in 1 second ( $\mathrm{FEV}_{1}$ ) according to ATS/ERS (http://www.thoracic.org/statements.) criteria and the International Olympic Committee $\left(\beta_{2}-\right.$ adrenoceptor agonists and the Olympic Games in Beijing; http://www.olympic.org).
Figure 1. Diagnostic algorithm for exercise-induced bronchoconstriction (EIB). NB: Criteria for bronchodilator reversibility and a positive provocation test result may vary (i.e. $>12 \%$ and $200 \mathrm{~mL}$ increase in forced expiratory volume in 1 second $\left(F E V_{1}\right)$. For more information see GINA 2011 document, ATS/ERS criteria and the International Olympic Committee ( $\beta_{2}$-adrenoceptor agonists and the Olympic Games in Beifing; http://www.olympic.org). It may also be necessary for athletes to repeat a bronchoprovocation test if negative initially. Note that other investigations such as marked peak flow variability may be used to support a diagnosis of asthma

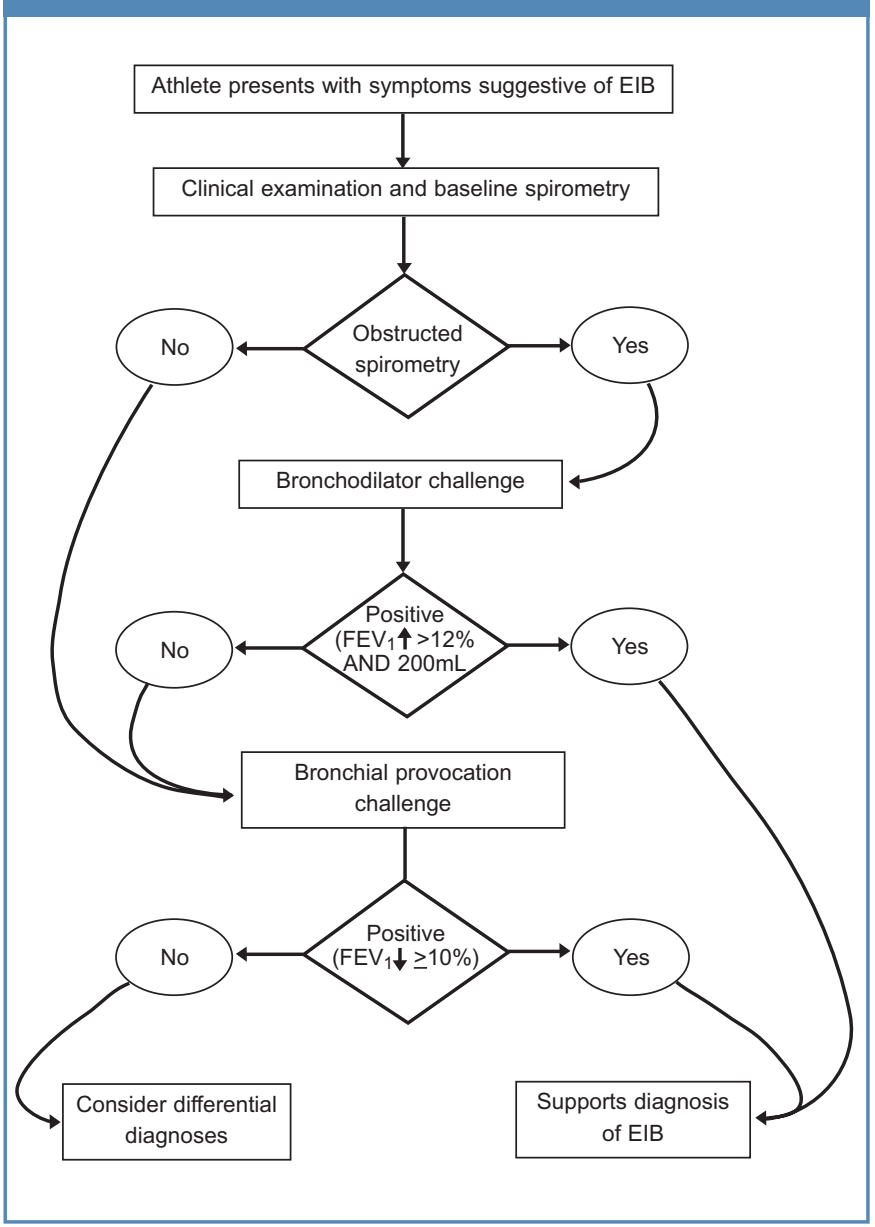

- Resting spirometry is usually normal in this setting ${ }^{16}$ and therefore a bronchial provocation challenge is necessary to establish evidence of variable airflow obstruction to demonstrate airway narrowing in response to a provocative substance (e.g. dry cold gas). Specifically, an athlete performs serial spirometry tests before and after a challenge, usually looking for a 10\% fall in $\mathrm{FEV}_{1}$.

- Exercise challenge tests, whilst intuitive, are not recommended as a first-line investigation given their poor sensitivity for diagnosis and the fact that they are difficult to perform reliably. ${ }^{17}$

- Direct access to bronchial provocation testing is generally poor in primary care, ${ }^{6}$ but a local lung physiology service will often be able to assist with testing. Alternatively, the mannitol 
bronchoprovocation test may prove feasible in a primary care setting,$^{18}$ but it is important for primary care physicians to be aware of specific protocol and safety precautions required to perform such tests.

- A diagnostic trial of therapy (e.g. with a short-acting $\beta_{2}$-agonist) without confirmatory objective testing is not recommended given the poor diagnostic value of symptoms. An athlete may not respond to first-line therapies and there may be overlap between EIB and other causes of exercise-related dyspnoea.

\section{Management}

Treatment options that should be considered and discussed with the athlete include both pharmacological and non-pharmacological interventions.

\section{Non-pharmacological}

- Performing a high-intensity interval warm-up (i.e. bursts of highintensity exercise interspersed with periods of low-intensity exercise) takes advantage of the refractory period in up to half of athletes and should be encouraged. ${ }^{8}$ In some cases it will be possible to provide sport-specific training advice that takes into account avoidance of triggers, timing of warm-up, and administration of inhalers.

- Enhanced humidification and warmth of the inspired air (e.g. by wearing a scarf or face muffle during training in very cold weather) may reduce the intensity of the provoking stimulus.

- Dietary interventions that may be beneficial include omega-3 acid supplementation ${ }^{19}$ and a low sodium diet. ${ }^{20}$

\section{Pharmacological}

- An inhaled short-acting $\beta_{2}$-agonist administered 15 mins before exercise is usually effective in negating EIB and forms the mainstay of treatment.

- Further treatment should be guided by the frequency of requirement of $\beta_{2}$-agonist therapy and the presence of additional symptoms. An athlete who has asthma symptoms outside the setting of exercise or who is frequently using $\beta_{2^{-}}$ agonist medication (i.e. more than three times per week) should be treated with a regular inhaled corticosteroid or an oral leukotriene antagonist.

- Physicians should be aware that frequent use of inhaled $\beta_{2^{-}}$ agonist medication is associated with drug tolerance, negating its efficacy, ${ }^{21}$ and will fail to control underlying airway inflammation.

- Associated nasal symptoms (e.g. rhinitis) should be assessed and effectively treated with topical nasal anti-inflammatory medication. ${ }^{22}$

- Exercise-induced asthma has a specific Quality and Outcomes Framework read code and athletes with EIB are likely to benefit from certain aspects of the follow-up within a standard asthma framework (e.g. attention to efficacy of treatment and inhaler technique).

It is important for athletes and physicians to be aware that some asthma medications remain on the World Anti-Doping Agency prohibited list. The majority of inhaled medications are no longer prohibited for use, but anti-doping guidance is frequently updated

\section{Key messages}

- $E I B$ is highly prevalent in athletic individuals.

- The diagnosis of EIB in athletes should not be made on clinical assessment alone; symptoms have poor predictive value and objective testing is therefore crucial to secure the diagnosis.

- A local respiratory physiology laboratory may assist with direct referrals for testing.

- Both pharmacological and non-pharmacological interventions should be considered when approaching treatment of EIB.

- Check online guidelines and advice for medication prescribing and warn competitive athletes that certain medications require notification to an athlete's governing body.

and therefore it is advisable to view the website (www.globaldro.org) or contact UK anti-doping for the latest specific guidance. Moreover, it is important to note that prescription of oral prednisolone still requires a therapeutic use exemption, a document providing supporting evidence of the clinical indication for treatment.

\section{Conclusions}

EIB is prevalent in athletes of all abilities and can impact on their health and performance. The majority of athletes are assessed and treated in primary care, so awareness of the need for an accurate diagnosis with objective tests and a pragmatic approach to treatment is vital to ensure best care for this unique population.

\section{Handling editor Jaime Correia de Sousa}

Acknowledgements We wish to thank Dr Henry Dean for his appraisal and comments on the manuscript.

Conflicts of interest The authors declare they have no conflicts of interest in respect of this document.

Contributorship All authors contributed equally to the preparation of this manuscript.

Funding $\mathrm{JHH}$ is supported by the National Institute for Health Research.

\section{References}

1. Anderson SD, Daviskas $\mathrm{E}$. The mechanism of exercise-induced asthma is .... J Allergy Clin Immunol 2000;106(3):453-9. http://dx.doi.org/10.1067/mai.2000.109822

2. Mannix ET, Roberts M, Fagin DP, Reid B, Farber MO. The prevalence of airways hyperresponsiveness in members of an exercise training facility. I Asthma 2003;40(4):349-55. http://dx.doi.org/10.1081/JAS-120018634

3. Dickinson JW, Whyte GP, McConnell AK, Harries MG. Impact of changes in the IOCMC asthma criteria: a British perspective. Thorax 2005;60(8):629-32. http://dx.doi.org/10.1136/thx.2004.037499

4. Hull JH, Ansley L, Garrod R, Dickinson JW. Exercise-induced bronchoconstriction in athletes: should we screen? Med Sci Sports Exerc 2007;39(12):2117-24. http://dx.doi.org/10.1249/mss.0b013e3181578db2

5. Weiler JM, Anderson SD, Randolph C, et al. Pathogenesis, prevalence, diagnosis, and management of exercise-induced bronchoconstriction: a practice parameter. Ann Allergy Asthma Immunol 2010;105(6 Suppl):S1-47. http://dx.doi.org/10.1016/ j.anai.2010.09.021

6. Hull JH, Hull PJ, Parsons JP, Dickinson JW, Ansley L. Approach to the diagnosis and management of suspected exercise-induced bronchoconstriction by primary care physicians. BMC Pulm Med 2009;9:29. http://dx.doi.org/10.1186/1471-2466-9-29

7. Backer V. Not all who wheeze have asthma. Breathe 2010;7:16-22 http://dx.doi.org/10.1183/18106838.0701.016

8. Stickland MK, Rowe BH, Spooner CH, Vandermeer B, Dryden DM. Effect of warm- 
up exercise on exercise-induced bronchoconstriction. Med Sci Sports Exerc 2012;44(3):383-91. http://dx.doi.org/10.1249/MSS.0b013e31822fb73a

9. Anderson SD, Kippelen P. Exercise-induced bronchoconstriction: pathogenesis. Curr Allergy Asthma Rep 2005;5(2):116-22. http://dx.doi.org/10.1007/s11882-005-0084-y

10. Helenius IJ, Tikkanen HO, Sarna S, Haahtela T. Asthma and increased bronchial responsiveness in elite athletes: atopy and sport event as risk factors. J Allergy Clin Immunol 1998;101(5):646-52. http://dx.doi.org/10.1016/\$0091-6749(98)70173-3

11. Bougault $\mathrm{V}$, Boulet LP. Airway dysfunction in swimmers. $\mathrm{Br}$ / Sports $\mathrm{Med}$ 2012;46(6):402-06. http://dx.doi.org/10.1136/bjsports-2011-090821

12. Dickinson J, McConnell A, Whyte G. Diagnosis of exercise-induced bronchoconstriction: eucapnic voluntary hyperpnoea challenges identify previously undiagnosed elite athletes with exercise-induced bronchoconstriction. Br I Sports Med 2010;45(14):1126-31. http://dx.doi.org/10.1136/bjsm.2010.072520

13. Ansley L, Kippelen $\mathrm{P}$, Dickinson J, Hull JH. Misdiagnosis of exercise-induced bronchoconstriction in professional soccer players. Allergy 2012;67(3):390-5. http://dx.doi.org/10.1111//.1398-9995.2011.02762.x

14. Rundell KW, Im J, Mayers LB, Wilber RL, Szmedra L, Schmidt HR. Self-reported symptoms and exercise-induced asthma in the elite athlete. Med Sci Sports Exerc 2001;33(2):208-13. http://dx.doi.org/10.1097/00005768-200102000-00006

15. Langdeau JB, Boulet LP. Is asthma over- or under-diagnosed in athletes? Respir Med 2003;97(2):109-14. http://dx.doi.org/10.1053/rmed.2003.1451
16. Bonini M, Lapucci G, Petrelli $G$, et al. Predictive value of allergy and pulmonary function tests for the diagnosis of asthma in elite athletes. Allergy 2007;62(10):116670. http://dx.doi.org/10.1111/j.1398-9995.2007.01503.x

17. Holzer $K$, Anderson SD, Douglass J. Exercise in elite summer athletes: challenges for diagnosis. J Allergy Clin Immunol 2002;110(3):374-80. http://dx.doi.org/10.1067/ mai.2002.127784

18. Turton JA, Glasgow NJ, Brannan JD. Feasibility and acceptability of using bronchial hyperresponsiveness to manage asthma in primary care: a pilot study. Prim Care Respir J 2012;21(1):28-34. http://dx.doi.org/10.4104/pcrj.2011.00079

19. Mickleborough TD, Murray RL, lonescu AA, Lindley MR. Fish oil supplementation reduces severity of exercise-induced bronchoconstriction in elite athletes. Am J Respir Crit Care Med 2003;168(10):1181-9. http://dx.doi.org/10.1164/rccm.200303$3730 \mathrm{C}$

20. Pogson Z, McKeever T. Dietary sodium manipulation and asthma. Cochrane Database Syst Rev 2011;(3):CD000436.

21. Anderson SD, Caillaud C, Brannan JD. Beta2-agonists and exercise-induced asthma. Clin Rev Allergy Immunol 2006;31:163-80. http://dx.doi.org/10.1385/ CRIAI:31:2:163

22. Dijkstra HP, Robson-Ansley P. The prevalence and current opinion of treatment of allergic rhinitis in elite athletes. Curr Opin Allergy Clin Immunol 2011;11(2):103-08. http://dx.doi.org/10.1097/ACI.0b013e3283445852

\section{Available online at http://www.thepcrj.org}

